10. Hanfling SM. Metastatic cancer to the heart. Review of the literature and report of 127 cases. Circulation. 1960 Sep;22:474-83.

11. Singla SL, Garg P, Tahlan RN. Gall bladder carcinoma presenting as liver abscess. Indian J Gastroenterol Off J Indian Soc Gastroenterol. 1998 Apr;17(2):68.

\section{Reversal of Vitiligo with Cure from Hepatitis-C Infection}

Hepatitis-C infection has been associated with various dermatological extra-hepatic manifestations. ${ }^{1}$ We report a patient of chronic hepatitis-C infection with vitiligo which improved on successful treatment of hepatitis-C infection.

\section{Case Report}

65-year-old lady was diagnosed with hepatitis-C related cirrhosis when she presented with an oesophageal variceal bleed for which she had undergone endoscopic variceal ligation. She gave history of a caesarean section 35 years ago with no history of blood transfusion, intravenous drug abuse, tattooing or any history suggestive of autoimmune disease in herself or her family. She gave history of skin de-pigmentation which started 5 years back on her face and gradually became generalised over next 2 years (Figure 1). She had generalised, well-defined, hypopigmented patches, suggestive of vitiligo and an enlarged liver palpable $2 \mathrm{~cm}$ below right costal margin. Investigations revealed WB Ccount:4300/ $\mathrm{mm}^{3}$, hemoglobin:11.8 g/dl, platelet count:88000/ $/ \mathrm{mm}^{3}$, total bilirubin:0.9 mg/dl, AST:250 IU/L,ALT:19 IU/L, alkaline phosphatase:180 IU/L (normal range 44-147 IU/L) and serum creatinine: $0.7 \mathrm{mg} / \mathrm{dl}$. The $\mathrm{HbA} 1 \mathrm{C}$ was $4.6 \%$, TSH:1.48 $\mu \mathrm{IU} / \mathrm{ml}$ (normal range 0.30-5.5 $\mu \mathrm{IU} / \mathrm{ml}$ ), ANA titre- 1:160, HBsAg and HIV were non-reactive. Anti-HCV was reactive with Hepatitis C viral load of 5,293,804 IU/ml(COBAS TaqMan technique) and genotype 3a. Ultrasonography abdomen was suggestive of cirrhosis with portal hypertension and ascites. She was started on PEG-interferon $\alpha$-2a 180 mcg subcutaneously weekly with ribavirin $800 \mathrm{mg} /$ day. She had not achieved a rapid virological response. After 2 months of initiating treatment, sofosbuvir was added to the treatment regime since it had become available in India. She received the three drugs-PEG-interferon, ribavarin and sofosbuvir for 6 months. Erythropoietin was administered as she developed ribavirin-induced anaemia, with lowest recorded haemoglobin being $8 \mathrm{~g} / \mathrm{dL}$. She achieved a rapid virological response at 1 month after initiation of the triple drug therapy. The vitiligo started improving around 3 months after initiation of this therapy, with reappearance of pigmented areas starting with her face and then extended to rest of her body (Figure 2). She achieved end of treatment response and sustained virological response at 12 and 24 weeks respectively post completion of therapy.

\section{Discussion}

Prevalence of HCV infection in India is $1.3 \%{ }^{2}$ Dermatological manifestations of HCV maybe a result of direct action of viral particles on keratinocytes, lymphocytes, antigen presenting cells and blood

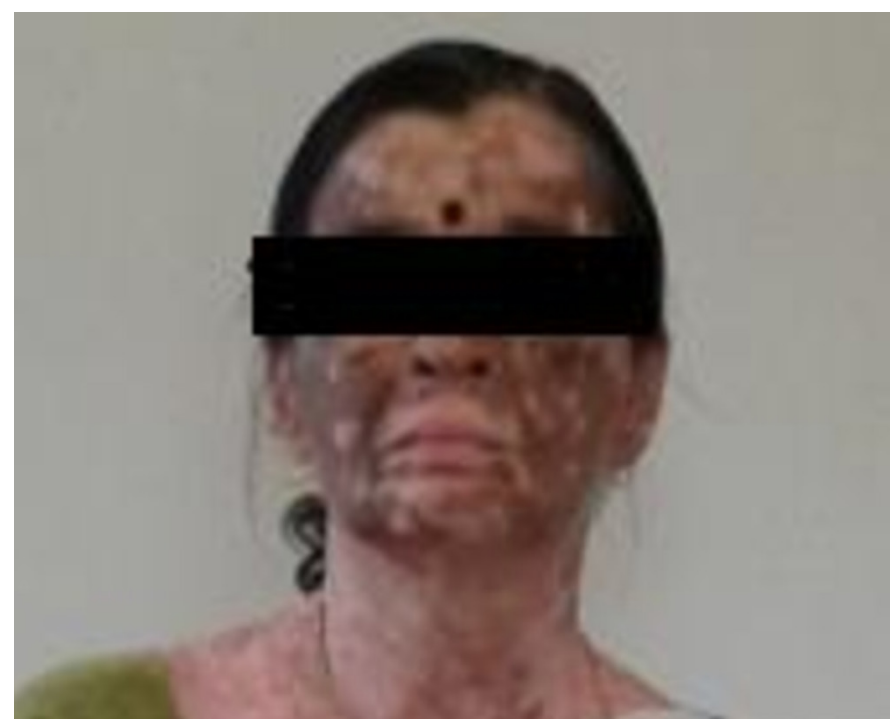

Figure 1: Vitiligo areas at the time of presentation. 


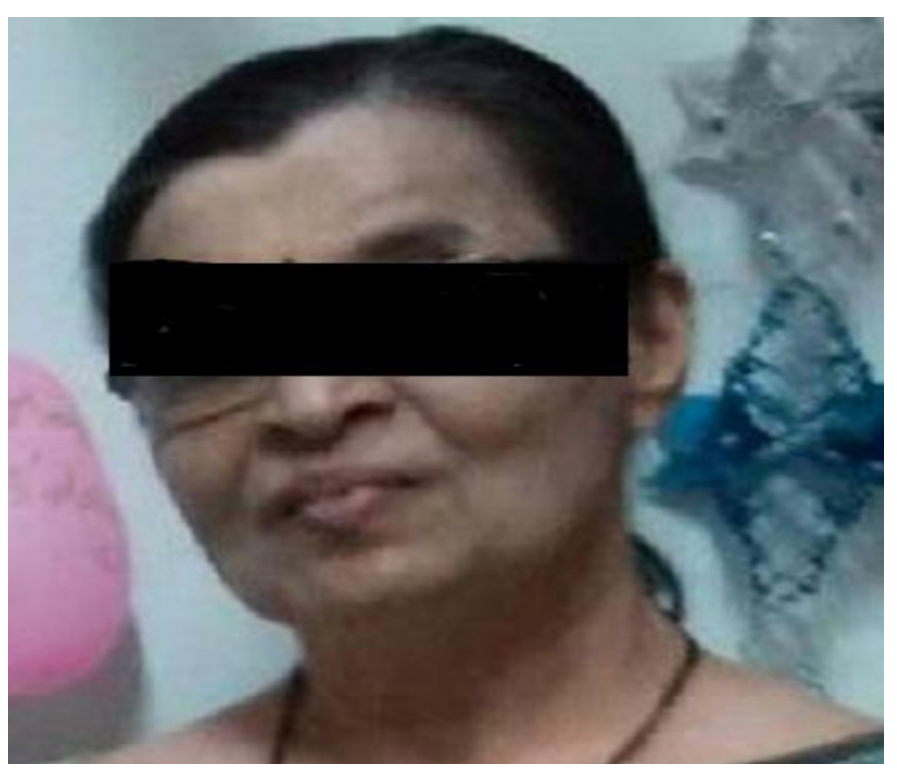

Figure 2: After initiating treatment, pigmentation gradually started reappearing. Image taken at the time of sustained virological response 24-weeks.

vessels. Furthermore, an indirect action may occur as an epiphenomenon related to an autoimmune process. ${ }^{3}$ The frequent skin manifestations described with $\mathrm{HCV}$ infection include vasculitis associated with cryoglobulinemia, lichen planus, porphyria cutaneatarda, necrolyticacral erythema, erythema multiforme, erythema nodosum, pruritus and psoriasis. ${ }^{4}$

Vitiligo affects $1 \%$ of the general population. ${ }^{3}$ It is an acquired depigmenting disorder of the skin in which melanocytes are destroyed. In our patient, we postulate the direct destruction of melanocyte DNA by the Hepatitis-C virus or indirectly it can be due to formation of immune complexes in the melanocytes or triggering of an autoimmune processes due to $\mathrm{HCV}$ infection. ${ }^{1}$

Our patient presented with a hepatitis-C virus infection and vitiligo. As the treatment was initiated, with the viral clearance the vitiligo started resolving. Such a case has been reported once before. ${ }^{5}$ In our patient, the vitiligo patches started resolving after 3 months of interferon, ribavirin and sofosbuvir which coincided with the reduction in viral load.

\section{NISHTHA NAGRAL ${ }^{1}$ \\ VIJAY DHAKRE ${ }^{2}$ \\ PREET SHAH ${ }^{1}$ \\ NIRZAR PARIKH ${ }^{1}$}

\author{
${ }^{1}$ Department of Medical Gastroenterlogy, \\ ${ }^{2}$ Department of Surgical Gastroenterlogy, \\ Jaslok Hospital and Research Centre, Mumbai \\ Corresponding Author: Dr Preet Shah \\ Email:drpreetshah@gmail.com
}

\section{References}

1. Fachinelli LR, Silva EC, Figueiredo M, Possa MS, Pelegrinelli FF, Molina RJ. Hepatitis C and cutaneous alterations. Rev. Soc. Bras. Med. Trop. Nov-Dec 2012; 45(6): 770-773.

2. Puri P, Anand AC, Saraswat VA, Acharya SK, Dhiman RK, Sarin SK, et al. Indian National Association for Study of the Liver (INASL) Guidance for Antiviral Therapy Against HCV Infection in 2015. JClinExpHepatol. 2015;5(3):221238.

3. Sène D, Limal N, Cacoub P. Hepatitis C virus-associated extrahepatic manifestations: a review. Metab Brain Dis. 2004;19(3-4):357-81.

4. Taffaro M, Pyrsopoulos N, Cedron H, Cacayorin E, Weppler $\mathrm{D}$, Moon J, et al. Vitiligo improvement in a hepatitis $\mathrm{C}$ patient after treatment with PEG-interferon alpha-2a and ribavirin: a case report. Dig Dis Sci. 2007;52(12):3435-7.

5. Sehgal VN, Srivastava G. Vitiligo: compendium of clinicoepidemiological features. Indian J DermatolVenereolLeprol. 2007;73(3):149-56. 